\title{
Predictors of mortality at one year after generalized convulsive status epilepticus
}

\author{
Kati Marjatta Tuppurainen ${ }^{\mathrm{a}, *}$, Jaakko Gabriel Ritvanen ${ }^{\mathrm{a}}$, Harri Mustonen ${ }^{\mathrm{b}}$, Leena Sinikka Kämppi ${ }^{\mathrm{a}}$ \\ a Clinical Neurosciences, Neurology, University of Helsinki and Department of Neurology, Helsinki University Central Hospital, Finland \\ b Department of Surgery, University of Helsinki and Helsinki University Central Hospital, Helsinki, Finland
}

\section{A R T I C L E I N F O}

\section{Article history:}

Received 7 June 2019

Accepted 4 July 2019

Available online $\mathrm{xxxx}$

\section{Keywords:}

Seizure

STESS

Long-term

Outcome

Treatment delay

Complication

\begin{abstract}
A B S T R A C T
Background: Status epilepticus (SE) is a life-threatening neurologic emergency, which requires prompt medical treatment. Little is known of the long-term survival of SE. The aim of this study was to investigate which factors influence 90 days and 1-year mortality after SE.

Materials and methods: This retrospective study includes all consecutive adult ( $>16$ years) patients $(\mathrm{N}=70)$ diagnosed with generalized convulsive SE (GCSE) in Helsinki University Central Hospital (HUCH) emergency department (ED) over 2 years. We defined specific factors including patient demographics, GCSE characteristics, treatment, complications, delays in treatment, and outcome at hospital discharge and determined their relation to 90 days and 1-year mortality after GCSE by using logistic regression models. Survival analyses at 1 year after GCSE were performed with Cox proportional hazards regression analysis.

Results: In-hospital mortality was $7.1 \%$. Mortality rate was $14.3 \%$ at 90 days and $24.3 \%$ at 1 year after GCSE. In the univariate logistic regression analysis, Status Epilepticus Severity Score $>4$ (STESS) (ODDS $=7.30, p=0.012$ ), worse-than-baseline condition at hospital discharge (ODDS $=3.5, p=0.006$ ), long delays in attaining seizure freedom (ODDS $=2.2, p=0.041$ ), and consciousness (ODDS $=3.4, p=0.014$ ) were risk factors for mortality at 90 days whereas epilepsy (ODDS $=0.2, p=0.014$ ) and Glasgow Outcome Scale (GOS) $>3$ at hospital discharge (ODDS $=0.05, p=0.006$ ) were protective factors. Risk factors for mortality at 1 year were STESS $>4$ (ODDS $=5.1, p=0.028$ ), use of vasopressors (ODDS $=8.2, p=0.049$ ), and worse-than-baseline condition at discharge (ODDS $=7.8, p=0.010)$ while $\mathrm{GOS}>3$ (ODDS $=0.2, p=0.005)$ was protective.

The univariate survival analysis at 1 year confirmed the significant findings regarding parameters STESS $>4$ (Hazard ratio $(\mathrm{HR})=4.1, p=0.009)$, worse-than-baseline condition $(\mathrm{HR}=6.2, p=0.015), \mathrm{GOS}>3(\mathrm{HR}=$ $0.2, p=0.004)$ at hospital discharge and epilepsy $(\mathrm{HR}=0.4, p=0.044)$. Additionally, diagnostic delay over $6 \mathrm{~h}(\mathrm{HR}=3.8, p=0.022)$ and Complication Burden Index $(\mathrm{CBI})$ as an ordinal variable $(0-2,3-6,>6)(\mathrm{HR}=$ $2.7, p=0.027)$ were predictive for mortality.

In the multivariate survival analysis, STESS $>4(\mathrm{HR}=5.1, p=0.007), \mathrm{CBI}(\mathrm{HR}=3.2, p=0.025$, ordinal variable), diagnostic delay over $6 \mathrm{~h}(\mathrm{HR}=7.2, p=0.003)$, and worse-than-baseline condition at hospital discharge (HR $=5.8, p=0.027$ ) were all independent risk factors for mortality at 1 year.

Conclusions: Severe form of SE, delayed recognition of GCSE, high number of complications during treatment period, and poor condition at hospital discharge are all independent predictors of long-term mortality. Most of these factors are also associated with mortality at 90 days, though at that point, delays in treatment seem to have a greater impact on prognosis than at 1 year.

This article is part of the Special Issue "Proceedings of the 7th London-Innsbruck Colloquium on Status Epilepticus and Acute Seizures
\end{abstract}

(c) 2019 Elsevier Inc. All rights reserved.
Abbreviations: ADL, active daily living; CBI, Complication Burden Index; CCI, Charlson Comorbidity Index; DA, data availability; EMS, emergency medical service; EMSE, epidemiology-based mortality score in status epilepticus; EMSE-EACE, epidemiologybased mortality score in status epilepticus, etiology-age-comorbidity-EEG; GOS, Glasgow Outcome Scale; HUCH, Helsinki University Central Hospital; LWAS, the weighted accuracy score; STESS, Status Epilepticus Severity Score.

* Corresponding author at: Majavatie 10 A 19, Helsinki, Finland.

E-mail addresses: kati.tuppurainen@hus.fi (K.M. Tuppurainen), jaakko.ritvanen@hus.fi (J.G. Ritvanen), Harri.mustonen@helsinki.fi (H. Mustonen), leena.kamppi@hus.fi (L.S. Kämppi).

\section{Introduction}

Status epilepticus (SE) is a life-threatening medical emergency, which requires prompt medical treatment and is associated with substantial morbidity and mortality. The incidence of SE ranges from 10 to 20 per 100,000 and mortality between 1.9 and $40 \%$ in published studies [1]. Factors related to poor short-term outcome include old age, symptomatic etiology, refractoriness, comorbidities, poor premorbid 
condition, long duration of SE, and complications and delays in the treatment [2-12]. Most of these outcome predictors have been incorporated in outcome scores Status Epilepticus Severity Score (STESS) [13], modified STESS (mSTESS) [8], and epidemiology-based mortality score in status epilepticus (EMSE) [14]. These scores have been developed for the in-hospital mortality prediction of SE. The predictive value of these scores has been externally validated, although the optimal predictive cutoff for STESS varies between the studies [15-17].

Up to date, the knowledge of long-term survival of SE is considerably more limited than that of short-term mortality. A recent review of altogether 37 studies reported a substantial long-term mortality with a wide range [18]. Ninety days mortality ranged from $14 \%$ to $50 \%$ [18-20], and mortality after at least 1-year of follow-up ranged from $23 \%$ to $57 \%$ $[6,18,21]$. There are only a few studies regarding factors affecting longterm mortality after SE, and the results are somewhat inconsistent. In most studies, symptomatic or potentially fatal etiology, older age, long duration of SE, refractoriness, and dependence in active daily living (ADL) functions have been shown to predict poor long-term outcome after SE $[6,18,22,23]$, however, there are also opposite results [24]. The predictive value of STESS for long-term mortality remains unconfirmed, since in some studies, it does not validate as a long-term predictor [18,24,25], although there are also promising results $[22,26,27]$. On the other hand, EMSE score has been associated with poor long-term outcome in one prospective study [27]. Still, the association of delays and complications in the treatment with long-term mortality remains undefined.

The aim of this study was to investigate which factors affect mortality of generalized convulsive SE (GCSE) after 90 days and 1 year.

\section{Materials and methods}

\subsection{Study design and setting}

This is a retrospective cohort study performed in Helsinki University Central Hospital (HUCH). This study conforms to the Finnish legislation concerning medical research, and the permission was granted by the HUCH Department of Neurology.

Helsinki University Central Hospital is a tertiary hospital serving a population of 1.4 million, and the emergency department (ED) offers $24 \mathrm{~h}$ neurological emergency service to the entire hospital district. In addition to $\mathrm{HUCH}$, the hospital district is served by seven regional hospitals with EDs run by internists and several healthcare centers. The local emergency medical service (EMS) is instructed to transport any patient independent in daily living with GCSE primarily to HUCH ED. At the time of the study period, EMS had the possibility to administer first- and third-stage treatments of SE, and second-stage treatment was administered in the ED.

\subsection{Definition of GCSE}

At the time of material collection, established SE was defined as continuous seizures lasting over $30 \mathrm{~min}$, several recurrent seizures without return of consciousness or occurrence of more than four seizures within any $1 \mathrm{~h}$ irrespective of return of consciousness in between. Patients having a convulsive seizure at any point of the SE period were considered as having convulsive SE (CSE). Patients with impaired consciousness, either primarily or secondarily, were considered as having generalized SE (GSE).

\subsection{Selection of participants}

This study includes 70 consecutive adult patients ( $\geq 16$ years) diagnosed with GCSE and treated in the HUCH ED between January 2002 and December 2003.

The patients were identified in the $\mathrm{HUCH}$ electronic patient database by the International Classification of Diseases Tenth Revision (ICD-10) code G41 (SE), yielding a total of 87 patients. Patients not meeting the criteria of GCSE were excluded. A total of 70 patients with GCSE were eligible for the study.

\subsection{Data collection}

Clinical data were collected by a trained medical doctor from the original medical records and recorded into an electronic database. Patient identification information was removed before further analyses.

Patient demographics, GCSE characteristics, parameters for treatment and complications, and measures of outcome were collected for all cases. These parameters are presented in Table 1 . In addition, we identified nine specific delay parameters in the management of GCSE, which are presented in Table 2 . For determining the accuracy and reliability of the collected time parameters, we calculated the weighted accuracy score $\left(\mathrm{L}_{\mathrm{WAS}}\right)$ and the data availability (DA), using the method developed for evaluation of retrospective delay materials [28].

Table 1

Patient demographics, GCSE characteristics, parameters for treatment, complications and outcome in the study material.

\begin{tabular}{|c|c|c|c|}
\hline \multicolumn{2}{|l|}{ Variable } & \multirow{2}{*}{$\frac{N}{70}$} & \multirow{2}{*}{$\frac{\%}{100}$} \\
\hline All & & & \\
\hline \multicolumn{4}{|l|}{ Demographics } \\
\hline \multirow[t]{2}{*}{ Gender } & Male & 35 & 50 \\
\hline & Female & 35 & 50 \\
\hline \multirow[t]{2}{*}{ Age under 65} & Yes & 51 & 72.9 \\
\hline & No & 19 & 27.1 \\
\hline \multirow[t]{3}{*}{ Epilepsy } & Yes & 46 & 65.7 \\
\hline & No & 23 & 32.9 \\
\hline & Unknown & 1 & 1.4 \\
\hline \multirow[t]{5}{*}{ Comorbidity (CCI) } & 0 & 18 & 25.7 \\
\hline & 1 & 16 & 22.9 \\
\hline & 2 & 18 & 25.7 \\
\hline & 3 & 10 & 14.3 \\
\hline & $>3$ & 8 & 11.4 \\
\hline Premorbid GOS & $1-3$ & 5 & 7 \\
\hline \multicolumn{4}{|l|}{ GCSE characteristics } \\
\hline \multirow[t]{4}{*}{ STESS } & 2 & 35 & 152.2 \\
\hline & 3 & 16 & 69.6 \\
\hline & 4 & 10 & 43.5 \\
\hline & 5 & 9 & 39.1 \\
\hline \multirow[t]{2}{*}{ Prestatus period } & Yes & 14 & 20.0 \\
\hline & No & 56 & 80.0 \\
\hline \multirow[t]{2}{*}{ SE onset } & Continuous & 45 & 64.3 \\
\hline & Intermittent & 25 & 35.7 \\
\hline \multirow[t]{2}{*}{ Refractoriness } & Non-SRSE & 38 & 54.3 \\
\hline & SRSE & 32 & 45.7 \\
\hline \multicolumn{4}{|l|}{ Treatment and complications } \\
\hline \multirow{3}{*}{ Anesthetic treatment } & No anesthesia & 8 & 11.4 \\
\hline & Only propofol & 56 & 80 \\
\hline & Multiple anesthetics & 6 & 8.6 \\
\hline \multirow[t]{2}{*}{ Burst-suppression obtained } & Yes & 30 & 42.9 \\
\hline & No & 40 & 57.1 \\
\hline \multirow[t]{2}{*}{ Complication burden index (CBI) } & $0-3$ & 38 & 54.3 \\
\hline & $>3$ & 32 & 45.7 \\
\hline \multirow[t]{2}{*}{ Use of vasopressors } & Yes & 51 & 72.9 \\
\hline & No & 19 & 27.1 \\
\hline \multirow[t]{2}{*}{ Mechanical ventilation } & Yes & 62 & 88.6 \\
\hline & No & 8 & 11.4 \\
\hline \multirow[t]{2}{*}{ Infections } & Yes & 61 & 87.1 \\
\hline & No & 9 & 12.9 \\
\hline \multicolumn{4}{|l|}{ Outcome } \\
\hline GOS at discharge & $\leq 3$ & 28 & 40 \\
\hline & $>3$ & 42 & 60 \\
\hline Condition at discharge & Worse-than-baseline & 41 & 58.6 \\
\hline & Baseline & 29 & 41.4 \\
\hline In-hospital mortality & Yes & 5 & 7.1 \\
\hline & No & 65 & 92.9 \\
\hline 90 d mortality & Yes & 10 & 14.3 \\
\hline & No & 60 & 85.7 \\
\hline 1 year mortality & Yes & 17 & 24.3 \\
\hline & No & 53 & 75.7 \\
\hline
\end{tabular}


Table 2

Delay parameters and the delays in the treatment.

\begin{tabular}{|c|c|c|c|c|c|c|c|}
\hline Variable & $\mathrm{N}$ & $\%$ & Time & Min & Max & DA & LWAS \\
\hline All cases & 70 & 100 & Median & & & $\%$ & \\
\hline \multicolumn{8}{|l|}{ Delays in the treatment } \\
\hline Onset-to-initial-treatment & 67 & 95.7 & $30 \mathrm{~min}$ & $0 \mathrm{~min}$ & 8 h 5 min & 97.0 & 1.8 \\
\hline Onset-to-diagnosis & 70 & 100 & $1 \mathrm{~h} 48 \mathrm{~min}$ & $6 \mathrm{~min}$ & $60 \mathrm{~h} 6 \mathrm{~min}$ & 97.1 & 1.5 \\
\hline Onset-to-second-stage-medication & 67 & 95.7 & $2 \mathrm{~h} 40 \mathrm{~min}$ & $30 \mathrm{~min}$ & 61 h $54 \mathrm{~min}$ & 98.5 & 1.6 \\
\hline Onset-to-tertiary-hospital (HUCH) & 70 & 100 & $2 \mathrm{~h} 25 \mathrm{~min}$ & $37 \mathrm{~min}$ & 277 h 40 min & 98.6 & 1.5 \\
\hline Onset-to-burst-suppression & 30 & 42.9 & $14 \mathrm{~h} 42 \mathrm{~min}$ & 5 h 5 min & $137 \mathrm{~h} 50 \mathrm{~min}$ & 100 & 1.5 \\
\hline Onset-to-seizure-freedom & 70 & 100 & $5 \mathrm{~h} 15 \mathrm{~min}$ & $26 \min$ & $533 \mathrm{~h} 15 \mathrm{~min}$ & 98.6 & 1.6 \\
\hline Onset-to-consciousness & 61 & 87.1 & $42 \mathrm{~h} 45 \mathrm{~min}$ & $2 \mathrm{~h} 40 \mathrm{~min}$ & $444 \mathrm{~h} 40 \mathrm{~min}$ & 96.7 & 1.4 \\
\hline Length-of-the-anesthesia-treatment & 62 & 88.5 & $38 \mathrm{~h}$ & $3 \mathrm{~h} 35 \mathrm{~min}$ & 238 h $52 \mathrm{~min}$ & 98.4 & 1.1 \\
\hline Length-of-the-ICU-treatment & 63 & 90 & $58 \mathrm{~h} 40 \mathrm{~min}$ & $7 \mathrm{~h} 45 \mathrm{~min}$ & 520 h $25 \mathrm{~min}$ & 100 & 1.1 \\
\hline
\end{tabular}

Outcome at hospital discharge was collected from medical records. Long-term mortality up to 1 year was gathered from the causes of death - register maintained by Official Statistics of Finland.

Missing events, e.g., no burst-suppression (BS), events happening during prestatus period, or unknown data were excluded from the final analysis. The missing data information is presented in Online Table 1.

\subsection{Definitions of measures}

Age of 65 years was selected as the classification basis for age as a grouping variable. Only patients with previously diagnosed epilepsy were considered as having epilepsy, previous epilepsy serving as surrogate for etiology of GCSE. Comorbidity was scored according to Charlson Comorbidity Index (CCI) [29]. Underlying etiologies for GCSE were not scored in CCI. Status Epilepticus Severity Score was calculated for all patients [13]. Seizures occurring up to $48 \mathrm{~h}$ prior to GCSE onset were referred to as prestatus period seizures. Seizures lasting at least $30 \mathrm{~min}$ clinically were defined as continuous. All other types of seizures were considered as intermittent. Patients' seizures failing to respond to first- or second-stage treatment were considered as refractory SE (RSE). Status epilepticus continuing or recurring $24 \mathrm{~h}$ or more after the onset of anesthesia was considered as superrefractory SE (SRSE). The anesthetic treatment was grouped as no anesthesia, only propofol or multiple anesthetics. For the evaluation of complications during treatment period, the Complication Burden Index (CBI) with a cutoff point of $>3$ and as a continuous variable were used [9]. Functional outcome at hospital discharge was considered good when condition returned to baseline and Glasgow Outcome Scale (GOS) was $>3$.

The onset of GCSE was defined as the beginning of the first seizure, fulfilling the criteria for established GCSE. Initial treatment was defined as the first given antiepileptic drug (AED), which was not necessarily the first-stage medication. The second-stage medication was defined as first given second-stage medication, mainly intravenous (i.v.) phosphenytoin. Diagnosis of GCSE was made by the EMS or ED physician on clinical grounds or with the aid of Electroencephalogram (EEG) recording. Tertiary hospital referred to HUCH ED at all times. The cessation of GCSE was defined with three separate parameters for the treatment response [28]: BS, clinical seizure freedom, and return of consciousness. Burst-suppression refers to the beginning of the first BS sequence during this SE. Clinical seizure freedom refers to the end of the last clinical convulsion, and return of consciousness refers to the time point, when the patient no longer presented with altered mental status. The length of treatment (anesthesia/Intensive Care Unit (ICU)) was calculated by adding up the total length of all individual anesthesia- / ICU-periods during the GCSE.

Long-term outcome of the patients was defined as mortality at 90 days, 1 year, or during the 1 -year follow-up period.

\subsection{Statistics}

Results are given as number of cases and percentage or median and interquartile range (IQR).

Ninety days and 1-year mortality were analyzed with univariate logistic regression analyses. Survival analyses at 1 year were performed with the Cox proportional hazards regression analysis and the Kaplan-Meier method with the log rank test.

Parameters for multivariate analysis at 1 year were selected based on univariate analyses and clinical relevance. Significant parameters correlating statistically or clinically were excluded from the multivariate models. Parameters selected for multivariate Cox proportional hazards analysis were STESS $>4, \mathrm{CBI}$ as an ordinal variable $(0-2,3-6,>6)$, worse-than-baseline condition at hospital discharge, and diagnostic delay with cutoff at $6 \mathrm{~h}$.

$p$ values $<0.05$ are considered significant, and two tailed tests were used. Statistical analyses were performed with the SPSS software (version 24.0, IBM Corp., NY, USA).

\section{Results}

In-hospital mortality was $7.1 \%$ in this study. Mortality rate was $14.3 \%$ at 90 days and $24.3 \%$ at 1 year after GCSE.

In the univariate logistic regression analysis, STESS $>4$ (ODDS $=$ 7.30, $p=0.012$ ), worse-than-baseline condition at hospital discharge (ODDS $=3.5, p=0.006$ ), long delays in attaining seizure freedom (ODDS $=2.2, p=0.041$ ), and long delays in gaining consciousness (ODDS $=3.4, p=0.014$ ) were risk factors for mortality at 90 days. Previously diagnosed epilepsy (ODDS $=0.2, p=0.014$ ) and good condition at hospital discharge evaluated with GOS $>3$ (ODDS $=0.05, p=$ 0.006 ) were protective factors regarding mortality at 90 days.

Status Epilepticus Severity Score $>4(\mathrm{ODDS}=5.1, p=0.028)$, use of vasopressors (ODDS $=8.2, p=0.049$ ), and worse-than-baseline condition at discharge (ODDS $=7.8, p=0.010$ ) were risk factors for mortality at 1 year, whereas GOS $>3$ at hospital discharge (ODDS $=0.2, p=$ 0.005 ) was protective.

Complication Burden Index was analyzed with a cutoff point of 3 , which proved insignificant for predicting mortality in this study. However, CBI as a continuous variable had slightly better but insignificant results in predicting both 90 days $(p=0.093)$ and 1 -year mortality $(p=$ 0.066 ) after GCSE. Delay parameters just not reaching statistical significance in predicting mortality at 90 days were onset-to-diagnosis-time $(p=0.054)$, onset-to-tertiary-hospital time $(p=0.05)$, onset-to-BS time ( $p=0.085)$, and length-of-ICU-treatment $(p=0.063)$. At 1 year, length-of-ICU-treatment remained slightly below significant association with mortality ( $p=0.057)$.

The results of the comprehensive univariate analysis are presented in Table 3.

The univariate survival analysis with Cox proportional hazards regression analysis at 1 year confirmed the significant findings regarding 
Table 3

The results of the comprehensive univariate analysis.

\begin{tabular}{|c|c|c|c|c|c|c|c|c|c|c|c|c|c|c|}
\hline \multicolumn{2}{|l|}{ Variable } & \multirow{3}{*}{$\begin{array}{l}\text { All cases } \\
\\
\mathrm{N}(\%)\end{array}$} & \multicolumn{6}{|l|}{90 days mortality } & \multicolumn{6}{|c|}{1 year mortality } \\
\hline & & & \multirow{2}{*}{$\begin{array}{l}\text { Dead } \\
\mathrm{N}(\%)\end{array}$} & \multirow{2}{*}{$\begin{array}{l}\text { Alive } \\
\mathrm{N}(\%)\end{array}$} & \multirow[b]{2}{*}{ ODDS } & \multirow{2}{*}{$\begin{array}{l}95 \% \\
\mathrm{CI} \\
\text { Min }\end{array}$} & \multirow{2}{*}{$\begin{array}{l}95 \% \mathrm{CI} \\
\operatorname{Max}\end{array}$} & \multirow[b]{2}{*}{$p$} & \multirow{2}{*}{$\begin{array}{l}\text { Dead } \\
\mathrm{N}(\%)\end{array}$} & \multirow{2}{*}{$\begin{array}{l}\text { Alive } \\
\mathrm{N}(\%)\end{array}$} & \multirow{2}{*}{$\overline{\text { ODDS }}$} & \multirow{2}{*}{$\begin{array}{l}95 \% \\
\mathrm{CI} \\
\overline{\mathrm{Min}}\end{array}$} & \multirow{2}{*}{$\begin{array}{l}95 \% \\
\mathrm{CI} \\
\operatorname{Max}\end{array}$} & \multirow[b]{2}{*}{$p$} \\
\hline & & & & & & & & & & & & & & \\
\hline Demographics & & $70(100)$ & $10(14)$ & $60(86)$ & & & & & $17(24)$ & $53(76)$ & & & & \\
\hline Gender & Male & $35(50)$ & $6(60)$ & $29(48)$ & 1.60 & 0.40 & 6.30 & 0.497 & $10(59)$ & $25(47)$ & 1.60 & 0.50 & 4.80 & 0.405 \\
\hline Age & $>65$ & $19(27)$ & $4(40)$ & $15(25)$ & 2.00 & 0.50 & 8.10 & 0.330 & $6(35)$ & $13(25)$ & 1.70 & 0.50 & 5.40 & 0.388 \\
\hline Epilepsy & Yes & $46(66)$ & $3(30)$ & $43(72)$ & 0.20 & 0.00 & 0.70 & 0.014 & $8(47)$ & $38(72)$ & 0.30 & 0.10 & 1.00 & $0.053^{*}$ \\
\hline $\mathrm{CCI}$ & $>2$ & $18(26)$ & $1(10)$ & $17(28)$ & 0.28 & 0.03 & 2.39 & 0.245 & $3(18)$ & $15(28)$ & 0.54 & 0.14 & 2.16 & 0.387 \\
\hline \multicolumn{15}{|c|}{ GCSE characteristics } \\
\hline STESS & $>2$ & $35(50)$ & $7(70)$ & $28(47)$ & 2.70 & 0.60 & 11.30 & 0.183 & $10(59)$ & $25(47)$ & 1.60 & 0.50 & 4.80 & 0.405 \\
\hline STESS & $>3$ & $19(27)$ & $4(40)$ & $15(25)$ & 2.00 & 0.50 & 8.10 & 0.330 & $6(35)$ & $13(25)$ & 1.70 & 0.50 & 5.40 & 0.388 \\
\hline STESS & $>4$ & $9(13)$ & $4(40)$ & $5(8)$ & 7.30 & 1.50 & 35.00 & 0.012 & $5(29)$ & $4(8)$ & 5.10 & 1.20 & 21.90 & 0.028 \\
\hline Prestatus period & Yes & $14(20)$ & $1(10)$ & $13(22)$ & 0.40 & 0.00 & 3.50 & 0.407 & $2(12)$ & $12(23)$ & 0.50 & 0.10 & 2.30 & 0.338 \\
\hline SE onset & Intermittent & $25(36)$ & $4(40)$ & $21(35)$ & 1.20 & 0.30 & 4.90 & 0.760 & $5(29)$ & $20(38)$ & 0.70 & 0.20 & 2.20 & 0.534 \\
\hline Refractoriness & SRSE & $32(46)$ & $6(60)$ & $26(43)$ & 2.00 & 0.50 & 7.70 & 0.333 & $9(53)$ & $23(42)$ & 1.50 & 0.50 & 4.40 & 0.493 \\
\hline \multicolumn{15}{|c|}{ Treatment and complications } \\
\hline treatment & Only propofol & $56(80)$ & $8(80)$ & $48(80)$ & 1.20 & 0.10 & 10.80 & 0.892 & $14(82)$ & $42(79)$ & 2.30 & 0.30 & 20.70 & 0.446 \\
\hline $\begin{array}{l}\text { Burst-suppression } \\
\text { Use of }\end{array}$ & Yes & $30(43)$ & $7(70)$ & $23(38)$ & 3.80 & 0.90 & 16.00 & $0.074^{*}$ & $9(53)$ & $21(40)$ & 1.70 & 0.60 & 5.10 & 0.227 \\
\hline vasopressors & Yes & $51(73)$ & $9(90)$ & $42(70)$ & 3.90 & 0.50 & 32.70 & 0.216 & $16(94)$ & $35(66)$ & 8.20 & 1.00 & 67.10 & 0.049 \\
\hline $\begin{array}{l}\text { Mechanical } \\
\text { ventilation }\end{array}$ & Yes & $62(89)$ & $9(90)$ & $53(88)$ & 1.20 & 0.10 & 10.80 & 0.878 & $16(94)$ & $46(87)$ & 2.40 & 0.30 & 21.30 & 0.422 \\
\hline CBI & $>3$ & $32(46)$ & $7(70)$ & $25(42)$ & 3.27 & 0.77 & 13.88 & 0.190 & $9(53)$ & $23(43)$ & 1.47 & 0.49 & 4.39 & 0.493 \\
\hline $\mathrm{CBI}$ & Continuous variable & $70(100)$ & $10(100)$ & $60(100)$ & 1.30 & 0.96 & 1.78 & $0.093^{*}$ & $17(100)$ & $53(100)$ & 1.29 & 0.98 & 1.70 & $0.066^{*}$ \\
\hline Infections & Yes & $61(87)$ & $10(100)$ & $51(85)$ & & & & 0.999 & $16(94)$ & $45(85)$ & 2.80 & 0.33 & 24.56 & 0.342 \\
\hline \multicolumn{15}{|c|}{ Outcome at hospital discharge } \\
\hline GOS & $>3$ & $42(60)$ & $1(10)$ & $41(68)$ & 0.050 & 0.006 & 0.436 & 0.006 & $5(29)$ & $37(70)$ & 0.18 & 0.05 & 0.60 & 0.005 \\
\hline Condition & Worse-than-baseline & $41(59)$ & $10(100)$ & $31(52)$ & 3.500 & 1.600 & $+\inf$ & 0.006 & $15(88)$ & $26(49)$ & 7.79 & 1.62 & 37.46 & 0.010 \\
\hline Delays & & $\begin{array}{c}\text { Time } \\
\text { h/(IQR) }\end{array}$ & Time h/(IQR) & $\begin{array}{c}\text { Time } \\
\text { h/(IQR) }\end{array}$ & & & & & $\begin{array}{c}\text { Time } \\
\text { h/(IQR) }\end{array}$ & $\begin{array}{c}\text { Time } \\
\text { h/(IQR) }\end{array}$ & & & & \\
\hline Onset-to-initial-tre & atment & $0.5(0.8)$ & $0.2(0.9)$ & $0.5(0.7)$ & 0.6 & 0.2 & 1.9 & 0.265 & $0.3(0.6)$ & $0.5(0.8)$ & 0.7 & 0.3 & 1.5 & 0.318 \\
\hline Onset-to-diagnosis & & $1.8(2.8)$ & $3(10.8)$ & $1.7(2.6)$ & 4.3 & 0.8 & 156.6 & $0.054^{*}$ & $2(5)$ & $1.6(2.6)$ & 1.9 & 0.5 & 12.4 & 0.26 \\
\hline Onset-to-second-st & age-treatment & $2.7(3.4)$ & $4.8(6.2)$ & $2.6(2.2)$ & 3.1 & 0.3 & 116.1 & 0.24 & $3.4(4.6)$ & $2.6(2.2)$ & 1.3 & 0.2 & 9 & 0.726 \\
\hline Onset-to-tertiary-h & ospital & $2.4(2.8)$ & $3.9(25)$ & $2.3(2.6)$ & 3.1 & 0.4 & 38.5 & $0.057^{*}$ & $2.4(3.9)$ & $2.4(2.6)$ & 1.6 & 0.3 & 6.8 & 0.412 \\
\hline Onset-to-burst-sup & pression & 14.7 (19) & $28.5(32.8)$ & $\begin{array}{c}12.5 \\
(18.3)\end{array}$ & 9.6 & 0.4 & $24,612.3$ & $0.085^{*}$ & $22(28.7)$ & $14(19.3)$ & 2.4 & 0.1 & 609 & 0.488 \\
\hline Onset-to-seizure-fr & eedom & $5.3(46.6)$ & $27.7(50.5)$ & $4.3(45.3)$ & 2.2 & 0.9 & 8.8 & 0.041 & $8.4(50.6)$ & $4.5(43.9)$ & 1.4 & 0.6 & 3.5 & 0.393 \\
\hline Onset-to-conscious & ness & $\begin{array}{c}42.8 \\
(42.8)\end{array}$ & $\begin{array}{c}59.5 \\
\left(56.25-89.33^{* *}\right)\end{array}$ & $\begin{array}{c}36.5 \\
(52.8)\end{array}$ & 3.4 & 1.6 & 12.2 & 0.014 & $\begin{array}{c}57.9 \\
(68.8)\end{array}$ & $38(53.1)$ & 2.2 & 0.6 & 12.5 & 0.226 \\
\hline Length-of-the-anes & thesia-treatment & $38(51.2)$ & $39.5(68.5)$ & $36(50.7)$ & 3.6 & 0.9 & 23.6 & 0.223 & $\begin{array}{c}36.9 \\
(66.2)\end{array}$ & $38(50.3)$ & 2 & 0.3 & 13.8 & 0.436 \\
\hline Length-of-the-ICU- & treatment & $\begin{array}{c}58.7 \\
(106.8)\end{array}$ & $85.3(112.6)$ & $\begin{array}{c}58.5 \\
(111.4)\end{array}$ & 3.4 & 0.9 & 23.6 & $0.063^{*}$ & $\begin{array}{c}62.3 \\
(101.8)\end{array}$ & $\begin{array}{c}58.5 \\
(109.6)\end{array}$ & 3.1 & 1 & 13.6 & $0.057^{*}$ \\
\hline
\end{tabular}

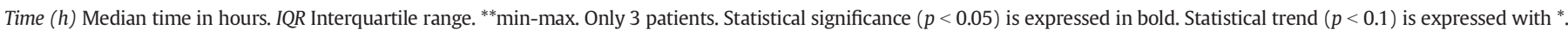

parameters STESS $>4(\mathrm{HR}=4.1,95 \%$ Confidence Interval $(\mathrm{CI})$ 1.43-11.67, $p=0.009$ ), worse-than-baseline condition (HR $=6.2,95 \% \mathrm{CI} 1.42-27.21$, $p=0.015), \mathrm{GOS}>3$ at hospital discharge ( $\mathrm{HR}=0.2,95 \% \mathrm{CI} 0.08-0.62, p=$ 0.004 ), and epilepsy (HR $=0.4,95 \% \mathrm{CI} 0.14-0.98, p=0.044)$. Vasopressor use $(\mathrm{HR}=6.92,95 \% \mathrm{CI} 0.92-52.2, p=0.061)$ and $\mathrm{CBI}$ as a continuous variable $(\mathrm{HR}=1.2,95 \% \mathrm{CI} 0.99-1.48, p=0.067)$ remained below the significance.

Continuous variables i.e., delays in treatment and $\mathrm{CBI}$ were tested for cutoffs with Receiver operating characteristic curve (ROC-curve) calculations. In survival analysis, diagnostic delay over $6 \mathrm{~h}(\mathrm{HR}=3.8,95 \% \mathrm{CI}$ $1.21-11.7, p=0.022)$ and $\mathrm{CBI}$ as an ordinal variable $(0-2,3-6,>6)$ $(\mathrm{HR}=2.7,95 \% \mathrm{CI} 1.12-6.6, p=0.027)$ were found to be predictive for mortality, as also seen in Kaplan-Meier curves (Figs. 1 and 2). Onsetto-burst-suppression time with a cutoff of $17.5 \mathrm{~h}(\mathrm{HR}=3.5,95 \% \mathrm{CI}$ $0.88-14.2, p=0.075$ ) was not quite statistically significant.

Results of the multivariate survival analysis are presented in Table 4. Status Epilepticus Severity Score $>4(\mathrm{HR}=5.1, p=0.007)$, CBI $(\mathrm{HR}=3.2, p=0.025$, ordinal variable $)$, diagnostic delay over $6 \mathrm{~h}(\mathrm{HR}=7.2, p=0.003)$, and worse-than-baseline condition at hospital discharge ( $\mathrm{HR}=5.8, p=0.027)$ were all independent risk factors for mortality at 1 year.

\section{Discussion}

This study brings notable additional information to the field of longterm outcome after GCSE by being the first study also investigating the effect of the delays and complications in the treatment on long-term mortality after GCSE.

Although delays are significant predictors of short-term outcome, the effect seems to reduce as time increases after GCSE. Consequently, at 90 days, several delays still have some effect on mortality while at one year, the effect on outcome has nearly been lost. However, diagnostic delay over $6 \mathrm{~h}$ remains a strong predictor for mortality. Additionally, poor functional outcome at hospital discharge, high number of complications during treatment period, and severity of GCSE graded with STESS proved to be independently associated with long-term mortality.

All retrospective studies bear a risk of reporting bias. To cover this bias, we used previously developed scores $\mathrm{L}_{\text {was }}$ and DA to determine the 
K.M. Tuppurainen et al. / Epilepsy \& Behavior xxx (xxxx) xxx

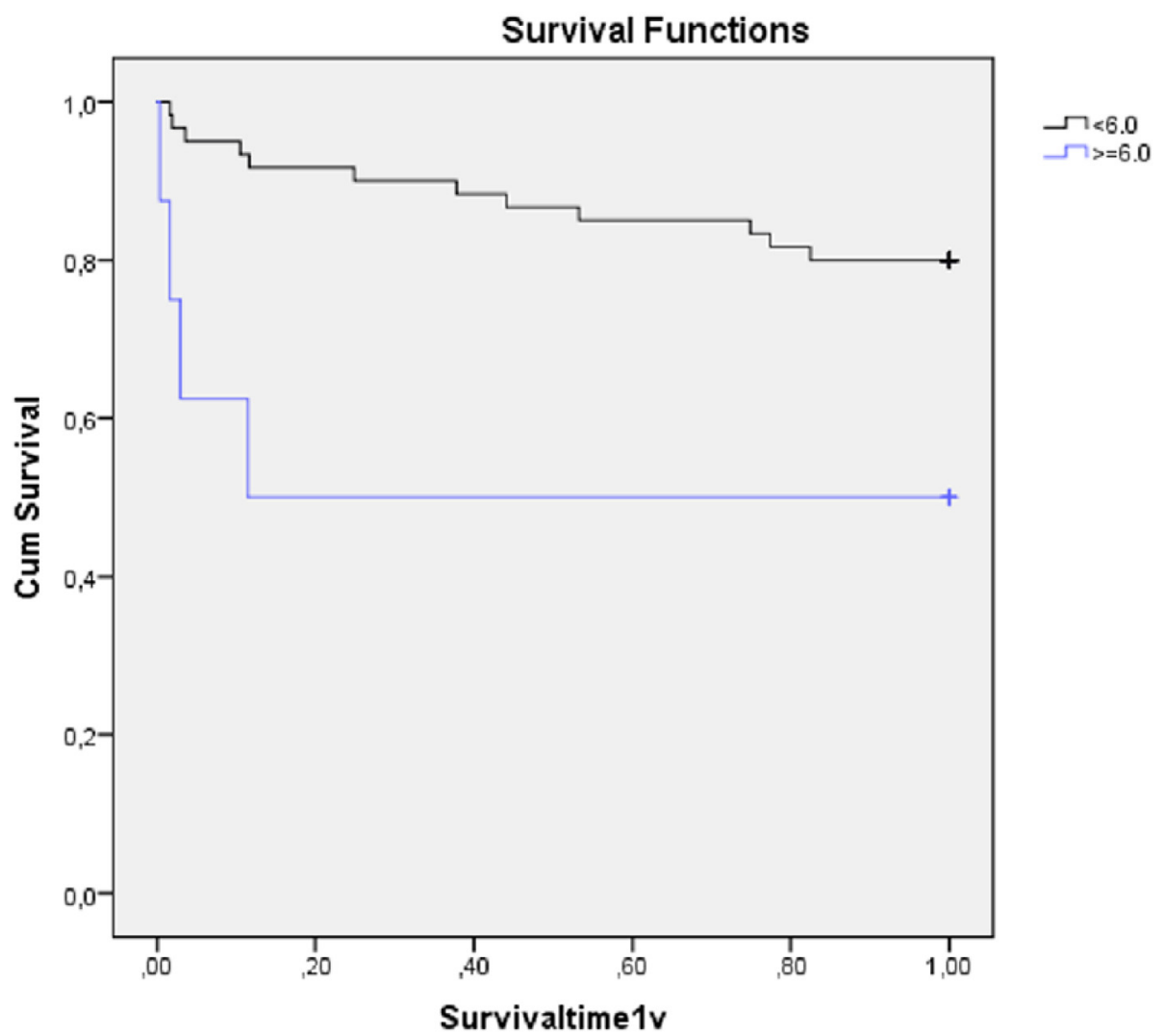

Fig. 1. Kaplan-Meier curve showing the significant difference of effect of the diagnostic delay ( $<6 \mathrm{~h}$ vs. $\geq 6 \mathrm{~h}$ ) on mortality during the 1 -year follow-up period after GCSE ( $p=0.014$ ).

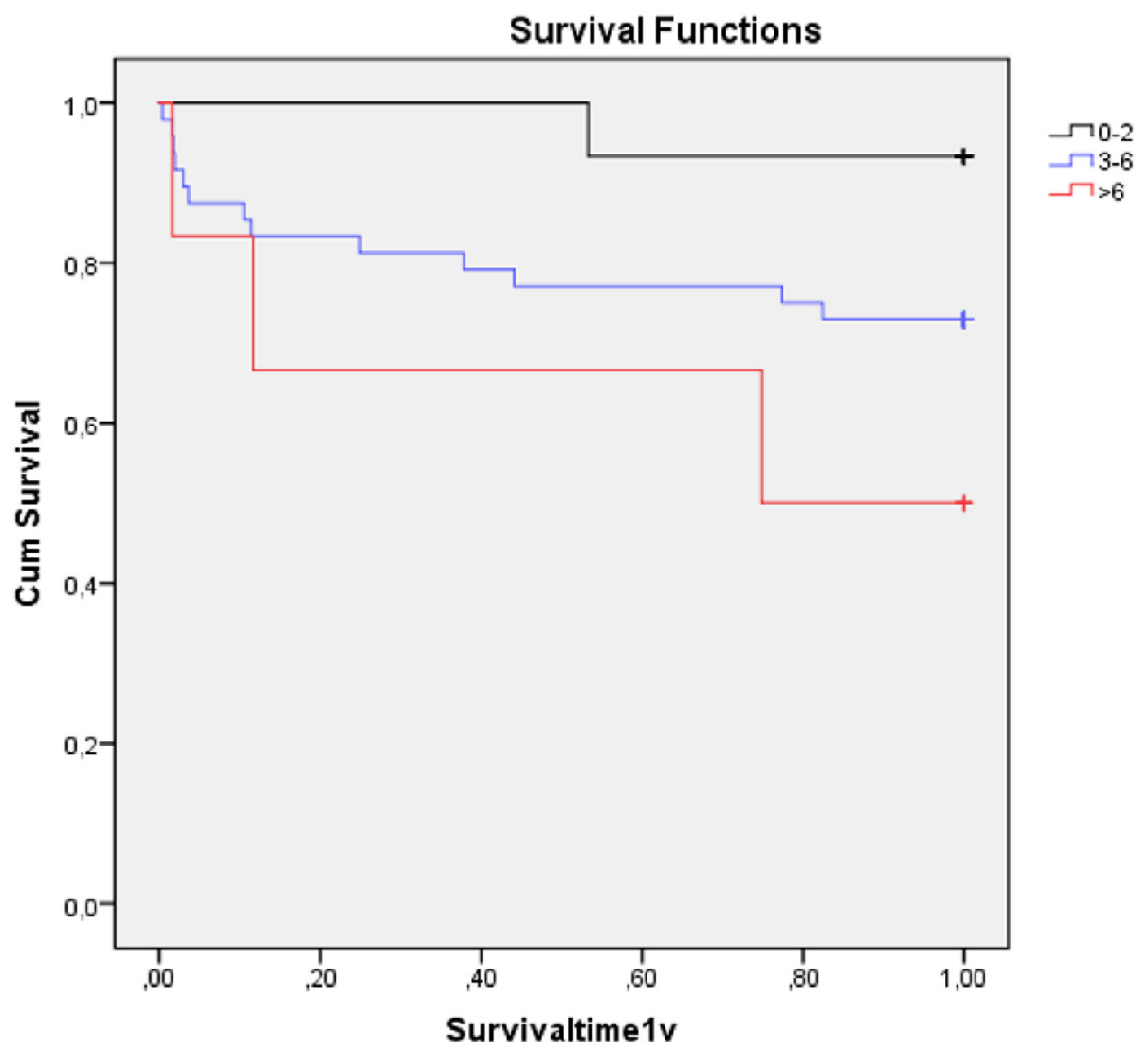

Fig. 2. Kaplan-Meier curve showing the significant difference of the CBI (0-2, 3-6, $>6$, ordinal variable) on mortality during the 1 -year follow-up period after GCSE ( $p=0.029)$. 
Table 4

The results of the multivariate survival analysis at 1 year after GCSE.

\begin{tabular}{|c|c|c|c|c|c|}
\hline \multirow[t]{2}{*}{ Variable } & & \multirow[t]{2}{*}{ HR } & \multirow{2}{*}{$\frac{95 \% \mathrm{CI}}{\mathrm{Min}}$} & \multirow{2}{*}{$\frac{95 \% \mathrm{CI}}{\operatorname{Max}}$} & \multirow[t]{2}{*}{$p$} \\
\hline & & & & & \\
\hline STESS & $>4$ & 5.13 & 1.57 & 16.77 & 0.007 \\
\hline CBI & $0-2 / 3-6 />6$ & 3.19 & 1.16 & 8.82 & 0.025 \\
\hline Onset-to-diagnosis & $>6 \mathrm{~h}$ & 7.19 & 1.92 & 26.99 & 0.003 \\
\hline Condition at discharge & Worse-than-baseline & 5.78 & 1.23 & 27.24 & 0.027 \\
\hline
\end{tabular}

accuracy and reliability of the collected time parameters. The Finnish EMS is very punctual in its markings guaranteeing a high level of accuracy, which is highlighted in a good $\mathrm{L}_{\text {was }}$ and DA throughout the study.

The material in this study is relatively old, and at the time of data collection, the definition of SE was a seizure lasting for at least $30 \mathrm{~min}$, instead of the current definition of $5 \mathrm{~min}$. However, the treatment protocols have not markedly changed during the past 15 years, and therefore, the material is comparable with studies with newer data. Nowadays, EEG recording in the acute phase is readily available in the ED in Helsinki whereas at the time of material collection, acutely registered EEG data were nearly lacking. For this reason, the calculation of EMSE score was not possible in this material.

The sample size is relatively small, which may be seen as the biggest limitation of our study. Nevertheless, it is fairly comparable with the sample sizes in previous studies. According to the patient distribution protocol, patients not independent in ADL functions are treated in regional hospitals and not in HUCH. Therefore, they are not included in this material. The large proportion of patients with RSE and SRSE in this material highlights the tertiary hospital status of $\mathrm{HUCH}$, where the most difficult cases of GCSE are treated in Southern Finland. These factors result in patient selection bias in our study population. However, it may enable us to diminish the effect of overall frailty of patients on long-term prognosis and focus more on the factors related solely to SE. These abovementioned limitations may warrant some precaution in interpreting the results of this study.

\subsection{Mortality}

Mortality increased from in-hospital mortality up to one year, when about one-fourth of the patients had died. While this seems quite high, it is, in fact, in the lower range of long-term mortality reported in previous studies [6,18-21]. This may partly reflect the overall good premorbid condition in our study population due to patient selection.

\subsection{Outcome score variables}

In this study, STESS was associated with poor long-term prognosis of GCSE with a score $>4$. Studies regarding the prognostic value of STESS as an indicator of long-term outcome have been published with opposing results [18,22,24-27]. In one study, all individual components of STESS except "history of previous seizures" seemed to be associated with long-term mortality, but overall STESS with a cutoff of 4 was not associated with survival after discharge [24]. The prognostic value of STESS for long-term outcome is still unclear, but the results of this present study are indicative of its usefulness in predicting long-term mortality, which possibly broadens the usability of the score and could serve as a basis for the future development of new outcome scores used for prediction of long-term outcome.

A few studies have investigated the role of EMSE score in predicting long-term outcome of SE with promising results [26,27]. In a recent study by Møller et al., epidemiology-based mortality score in status epilepticus, etiology-age-comorbidity-EEG (EMSE-EACE) was significantly associated with mortality after discharge, but in the same patients, STESS $\geq 3$ reached only borderline significance and STESS $\geq 4$ was not statistically significant [26]. Because of the lacking EEG recordings on hospital admission for most of the cohort, EMSE score could not be determined in this study.

The protective value of previous epilepsy on mortality seen in this study possibly reflects the worse prognosis of severe symptomatic causes resulting in SE. This finding is in line with other studies, where acute symptomatic, progressive symptomatic, and potentially fatal etiologies have been seen to predict long-term mortality [18,23,27,30]. Although Kantanen et al. could not confirm the positive predictive value of earlier epilepsy at 1 year after SE, they found that the poor outcome in patients with preexisting epilepsy was related to remote symptomatic etiology or to a progressive syndrome, indicating that also, patients with epilepsy are at risk for etiologies with unfavorable outcome [24].

Older age has been associated with worse long-term outcome $[6,18$, 30], but individual patients up to the age of 79 years have been reported to recover functionally after RSE [24]. In our study, we could not confirm the significance of age as an individual parameter predicting long-term mortality. This finding may at least partly be explained by the patient distribution protocol in $\mathrm{HUCH}$ area directing patients dependent in ADL functions to regional hospitals. Since dependence of aid due to illness and frailty is more common in the elderly population, the patient selection might influence our results regarding the prognostic value of age on mortality. The effect of the premorbid condition on the long-term prognosis has been reported earlier [6]. Because of the patient distribution protocol in $\mathrm{HUCH}$, only a clear minority of patients in our material had a premorbid GOS of $<4$, thus, the effect on mortality could not be analyzed.

\subsection{Functional outcome at hospital discharge}

Only one study has previously reported the significance of condition at hospital discharge on long-term mortality, where modified Rankin Scale ( $\mathrm{mRS})>2$ was the predictor [31]. In our study, the condition at discharge was evaluated categorically with GOS and comparatively to baseline condition prior SE. Poor condition in any of these measures was a significant predictor of mortality at 1 year after GCSE. Since associations between delays in the treatment and functional outcome at discharge have been reported [11], this new finding highlights even more the importance of how effectively patients with SE should be managed in the early phases of the SE.

\subsection{Duration of SE and delays in the treatment}

Long duration of SE is a reported risk factor for long-term mortality $[18,22,23]$. Definition of SE duration alternates between SE studies, since the exact endpoint of SE is conceptually problematic and used definitions contain variability [32,33]. We used stepwise definition for the end of GCSE as described in Section 2.5 and found that the longer the duration from SE onset to seizure-freedom and to return of consciousness, the higher the mortality rate at three months after GCSE. A previous study of this same cohort showed that delay in return of consciousness was related to poor outcome at hospital discharge and in-hospital mortality [11]. Interestingly, predictive association of this delay with mortality found at discharge and at 90 days was lost at 1-year follow-up.

Delays in the treatment of SE are associated with short-term outcome among both pediatric and adult patients $[11,12]$. The need to minimize delays and optimize every component in the treatment chain has been shown to be an important determinant of outcome [11]. None of the previous studies have focused on the effect of delays on long-term mortality. Although most of the delays in treatment in our study did not reach significance, several delays showed trend-like effect on mortality at 90 days. Nonetheless, we found that if the delay in diagnosing GCSE exceeded $6 \mathrm{~h}$, it had a significant effect on long-term survival. The same phenomenon has been reported with short-term outcome, where diagnostic delay over $2.4 \mathrm{~h}$ was predictive [11]. These findings elucidate the importance of early diagnosis of SE. Electroencephalogram (EEG) is not available in EMS, and 24/7 EEG-recording possibilities are lacking in most of the EDs. Therefore, the diagnosis of SE in the early 
phases of the treatment is based on clinical judgment. Recently published ADAN scale (Abnormal speech, eye deviation, automatism, number of seizures) might bring some help for the clinical evaluation [34]; however, substantial effort should be accomplished to improve the diagnostic facilities.

\subsection{Refractoriness and ICU treatment}

Superrefractoriness in SE has been reported to be an independent risk factor for long-term mortality in a material based on ICU-treated SE cases [6]. This relation between superrefractoriness and long-term mortality could not be confirmed in this study, which might be partly explained by the different study designs.

Refractory cases mostly require ICU treatment, which might be prolonged especially in SRSE cases. Prolonged hospital and ICU treatment periods are associated with poor outcome and mortality at hospital discharge $[4,10]$. On the contrary, a previous study concluded that the length of ICU treatment did not differ between patients with good and poor long-term outcomes [24]. This finding is partially in line with our results, where the length of ICU treatment was not an independent predictor of long-term mortality, although a trend-like association was found.

In earlier studies, intravenous anesthetic drug (IVAD) treatment itself has not been associated with short-term mortality [35] nor the long-term mortality after SE [22]. These findings are supported by our results. We could neither find difference between the use of propofol only compared with the use of multiple anesthetics. Long anesthesia time has been associated with poor short-term outcome [11,36], however, similar association was not found in predicting long-term mortality in this present study.

Treatment complications increase as the length of the SE period increases [37], and complications might be one of the reasons for poor outcome in long SE treatment episodes [4]. Intensive Care Unit (ICU) and IVAD treatments are risk factors for infections, hypotension, need for intubation and mechanical ventilation, and other systemic complications [3, 38]. Vasopressor use, infections, and mechanical ventilation have been associated with short-term outcome in previous publications $[10,36,39]$. Most of these factors do not increase long-term mortality [22], however, sepsis and severity of organ dysfunction (Sequential Organ Failure Assessment Score (SOFA score)) are associated with poor long-term outcome [6, 22 ]. In this study, vasopressor use was associated with mortality at one year. Furthermore, our study showed that an increasing total number of complications was independently associated with long-term mortality. This finding increases the importance of high quality in intensive care but also underlines the importance of measures taken to prevent nonrefractory SE evolving to RSE.

\section{Conclusion}

Results of this study show that the severity of SE, number of treatment complications, diagnostic delay over $6 \mathrm{~h}$, and poor functional condition at hospital discharge have significant effect on long-term prognosis of GCSE. These findings demand for aggressive treatment of SE aiming for early seizure termination, shorter treatment periods, and fewer complications during the treatment. Our study underlines the importance of rapid diagnostics of SE also on long-term survival, highlighting the need for EMS personnel education, on-call EEG availability and development, and implementation of SE recognition algorithms.

Interestingly, our study showed that prognostic factors for mortality changed over the 1-year follow-up period, from 90 days to 1 year, thus, it is presumable that the predictive factors keep on changing as time passes by. The knowledge of mortality and causes of death during a longer follow-up period than 1 year is limited, which claims for further studies.

Supplementary data to this article can be found online at https://doi. org/10.1016/j.yebeh.2019.07.012.

\section{Declaration of Competing Interest}

None.

\section{Acknowledgments}

This study has been financially supported by HUCH Neurological Department Research Grant.

We confirm that we have read the Journal's position on issues involved in ethical publication and affirm that this report is consistent with those guidelines.

\section{References}

[1] Rosenow F, Hamer HM, Knake S. The epidemiology of convulsive and nonconvulsive status epilepticus. Epilepsia 2007;48:82-4.

[2] Neligan A, Shorvon SD. Prognostic factors, morbidity and mortality in tonic-clonic status epilepticus: a review. Epilepsy Res 2011;93:1-10.

[3] Sutter R, Kaplan PW, Rüegg S. Outcome predictors for status epilepticus-what really counts. Nat Rev Naurol 2013;9:525-34.

[4] Claassen J, Lokin J, Fitzsimmons B, Mendelsohn FA, Mayer SA. Predictors of functional disability and mortality after status epilepticus. Neurology 2002;58: 139-42.

[5] Agan K, Afsar N, Midi I, Us O, Aktan S, Aykut-Bingol C. Predictors of refractoriness in a Turkish status epilepticus data bank. Epilepsy Behav 2009;14:651-4.

[6] Kantanen AM, Kälviäinen R, Parviainen I, Ala-Peijari M, Bäcklund T, Koskenkari J, et al. Predictors of hospital and one-year mortality in intensive care patients with refractory status epilepticus: a population-based study. Crit Care 2017;21:71.

[7] Krishnamurthy KB, Drislane FW. Relapse and survival after barbiturate anesthetic treatment of refractory status epilepticus. Epilepsia 1996;37:863-7.

[8] Gonzalez-Cuevas M, Santamarina E, Toledo M, Quintana M, Sala J, Sueiras M, et al. A new clinical score for the prognosis of status epilepticus in adults. Eur J Neurol 2016; 23:1534-40

[9] Kämppi L, Ritvanen J, Strbian D, Mustonen H, Soinila S. Complication Burden Index a tool for comprehensive evaluation of the effect of complications on functional outcome after status epilepticus. Epilepsia 2018;59:176-81.

[10] Sutter R, Tschudin-Sutter S, Grize L, Fuhr P, Bonten MJ, Widmer AF, et al. Associations between infections and clinical outcome parameters in status epilepticus: a retrospective 5-year cohort study. Epilepsia 2012;53:1489-97.

[11] Kämppi L, Mustonen H, Kotisaari K, Soinila S. The essence of the first $2.5 \mathrm{~h}$ in the treatment of generalized convulsive status epilepticus. Seizure 2018;55:9-16.

[12] Gaínza-Lein M, Sánchez Fernández I, Jackson M, Abend NS, Arya R, Brenton JN, et al. Association of time to treatment with short-term outcomes for pediatric patients with refractory convulsive status epilepticus. JAMA Neurol 2018;75(4):410-8.

[13] Rossetti AO, Logroscino G, Bromfield EB. A clinical score for prognosis of status epilepticus in adults. Neurology 2006;66:1736-8.

[14] Leitinger M, Höller Y, Kalss G, Rohracher A, Novak HF, Höfler J, et al. Epidemiology-based mortality score in status epilepticus (EMSE). Neurocrit Care 2015;22:273-82.

[15] Sutter R, Kaplan PW, Rüegg S. Independent external validation of the Status Epilepticus Severity Score. Crit Care Med 2013:41:e475-9.

[16] Kang BS, Kim DW, Kim KK, Moon HJ, Kim Y-S, Kim HK, et al. Prediction of mortality and functional outcome from status epilepticus and independent external validation of STESS and EMSE scores. Crit Care 2016:20:25.

[17] Giovannini G, Monti G, Tondelli M, Marudi A, Valzania F, Leitinger M, et al. Mortality, morbidity and refractoriness prediction in status epilepticus: comparison of STESS and EMSE scores. Seizure 2017;46:31-7.

[18] Sculier C, Gainza M, Sánches Fernándes I, Loddenkemper T. Long-term outcomes of status epilepticus: a critical assessment. Epilepsia 2018;59:155-69.

[19] Legriel S, Lemiale V, Schenck M, Chelly J, Laurent V, Daviaud F, et al. Hypothermia for neuroprotection in convulsive status epilepticus. N Engl J Med 2016:375:2457-67.

[20] Lai A, Outin H, Jabot J, Mégarbane B, Gaudry S, Coudroy R, et al. Functional outcome of prolonged refractory status epilepticus. Critical Care 2015;19:199.

[21] Cooper A, Jeffrey W, Britton MD. Functional and cognitive outcome in prolonged refractory status epilepticus. Arch Neurol 2009;66:1505-9.

[22] Madžar D, Geyer A, Knappe RU, Gollwitzer S, Kuramatsu JB, Gerner ST, et al. Association of seizure duration and outcome in refractory status epilepticus. J Neurol 2016; 263:485-91.

[23] Logroscino G, Hesdorffer DC, Cascino GD, Annegers JF, Bagiella E, Hauser WA. Longterm mortality after a first episode of status epilepticus. Neurology 2002;58:537-41.

[24] Kantanen AM, Reinikainen M, Parviainen I, Kälviäinen R. Long-term outcome of refractory status epilepticus in adults: a retrospective population-based study. Epilepsy Res 2017;133:13-21.

[25] Auckland P, Lando M, Vilholm O, Christiansen EB, Beier CP. Predictive value of the status epilepticus severity score (STESS) and its components for long-term survival. BMC Neurol 2016;16:213.

[26] Møller HS, Rodin E, Auckland P, Lando M, Christiansen EB, Beier CP. Epidemiologybased mortality score is associated with long-term mortality after status epilepticus. Neurocrit Care 2019. https://doi.org/10.1007/s12028-018-0663-0.

[27] Atmaca MM, Bebek N, Baykan B, Gökyiğit A, Gürses C. Predictors of outcomes and refractoriness in status epilepticus: a prospective study. Epilepsy Behav 2017;75: $158-64$ 
[28] Kämppi L, Mustonen H, Soinila S. Analysis of the delay components in the treatment of status epilepticus. Neurocrit Care 2013;19:10-8.

[29] Charlson ME, Pompei P, Ales KL, MacKenzie CR. A new method of classifying prognostic comorbidity in longitudinal studies: development and validation. J Chronic Dis 1987:40:373-8.

[30] Ristic AJ, Sokic DV, Trajkovic G, Janković S, Vojvodić NM, Bascarević V, et al. Longterm survival in patients with status epilepticus: a tertiary referral center study. Epilepsia 2010;51:57-61.

[31] Rodin E, Krogstad MH, Aukland P, Lando M, Møller HS, Gesche J, et al. High longterm mortality after incident status epilepticus in adults: results from a population based study. Epilepsia 2019;60:33-41.

[32] Rantsch K, Walter U, Wittstock M, Benecke R, Rösche J. Treatment and course of different subtypes of status epilepticus. Epilepsy Res 2013;107:156-62.

[33] Drislane F, Blum A, Lopez M, Gautam S, Schomer DL. Duration on refractory status epilepticus and outcome: loss of prognostic utility after several hours. Epilepsia 2009;50:1566-71.
[34] Requena M, Fonseca E, Olivé M, Abraira L, Quintana M, Mazuela G, et al. The ADAN Scale: a proposed scale for prehospital use to identify status epilepticus. Eur J Neurol 2019;26:760-e55.

[35] Alvarez V, Lee JW, Westover MB, Drislane FW, Novy J, Faouzi M, et al. Therapeutic coma for status epilepticus: differing practices in a prospective multicenter study. Neurology 2016;87:1650-9.

[36] Hocker SE, Britton JW, Mandrekar JN, Wijdicks EF, Rabinstein AA. Predictors of outcome in refractory status epilepticus. JAMA Neurol 2013;70:72-7.

[37] Aminoff M, Simon R. Status epilepticus: causes, clinical features and consequences in 98 patients. Am J Med 1980;69:657-66.

[38] Sutter R, Marsch S, Fuhr P, Kaplan PW, Rüegg S. Anesthetic drugs in status epilepticus: risk or rescue? Neurology 2014;82:656-64.

[39] Kowalski RG, Ziai WC, Rees RN, Werner Jr JK, Kim G, Goodwin H, et al. Third-line antiepileptic therapy and outcome in status epilepticus: the impact of vasopressor use and prolonged mechanical ventilation. Crit Care Med 2012;40: 2677-84. 